\title{
Investigation of a Modified Cobalt-Free Alloy for Nuclear Application
}

\author{
Mamdouh Mahmoud Eissa', Maged Mahmoud Kassab ${ }^{2}$, Samir Uoshaa El-Kameesy³, \\ Ahamed Abdel-Latif Mohamed2* \\ ${ }^{1}$ Department of Steel and Ferroalloys, CMRDI, Helwan, Egypt \\ ${ }^{2}$ Department of Physics, Faculty of Engineering, Fayoum University, Fayoum, Egypt \\ ${ }^{3}$ Department of Physics, Faculty of Science, Ain Shams University, Cairo, Egypt \\ Email: ahmed@fayoum.edu.eg
}

Received 21 August 2015; accepted 20 September 2015; published 23 September 2015

Copyright (C) 2015 by authors and Scientific Research Publishing Inc.

This work is licensed under the Creative Commons Attribution International License (CC BY).

http://creativecommons.org/licenses/by/4.0/

c) (i) Open Access

\begin{abstract}
Cobalt-free alloy of constituent's “0.045\%C-12.73\%Ni-6.53\%Cr-3.2\%Mo-0.02\%Ti-0.01\%V” has been prepared by electro slag remelting technique. Mass attenuation coefficient, half value layer and effective atomic number have been determined for the prepared sample at photon energies 235 $2700 \mathrm{keV}$. The results are compared with the corresponding theoretical calculations based on XCOM program and a fair agreement is obtained.
\end{abstract}

\section{Keywords}

Cobalt Free, Gamma Shielding, Effective Atomic Number, Mass Attenuation Coefficient

\section{Introduction}

Attributing to increasing the use of radioactive sources in different fields such as medicine, tomography, and nuclear research applications, the researchers have focused on studying the photon interactions with matter (attenuation coefficients) as radiation is part of our life. In this work, the author prepared Cobalt-free alloy by electro slag remelting technique, and then mass attenuation coefficient, half value layer and effective atomic number had been determined at photon energies 235 - $2700 \mathrm{keV}$ by using different point radioactive sources ( ${ }^{133} \mathrm{Ba}$, ${ }^{137} \mathrm{Cs},{ }^{60} \mathrm{Co}$ and $\left.{ }^{232} \mathrm{Th}\right)$. The results showed that the calculated and measured values were in good agreement.

\section{Experimental Procedure}

The cobalt-free steel sample was prepared in the steel Technology Department, CMRDI, Egypt, using pilot plant

${ }^{*}$ Corresponding author.

How to cite this paper: Eissa, M.M., Kassab, M.M., El-Kameesy, S.U. and Mohamed, A.A.-L. (2015) Investigation of a Modified Cobalt-Free Alloy for Nuclear Application. Journal of Materials Science and Chemical Engineering, 3, 52-56.

http://dx.doi.org/10.4236/msce.2015.39007 
induction furnace electro slag remelting technique (ESR). The produced steels were hot forged followed by air cooling. The hot forged steels were subjected to solution treatment $\left(820^{\circ} \mathrm{C}\right.$ - for 1 hour $)$, with the aging process $\left(480^{\circ} \mathrm{C}\right.$-for 2 hours) [1]-[5].

The mass attenuation coefficient of gamma radiation was measured with a narrow beam array using gamma spectroscopy technique in the Physics Department, Faculty of Science, Ain Shams University, Egypt. The arrangement of the device consists of hyper pure germanium (HPGe) detector with relative efficiency $\sim 30 \%$ relative to a 3" X 3" NaI (Tl) detector connected to multichannel pulse height analyzer.

The samples were radiated by photons emitted from ${ }^{60} \mathrm{Co},{ }^{133} \mathrm{Ba},{ }^{137} \mathrm{Cs}$ and ${ }^{232} \mathrm{Th}$ radioactive point sources in the range (238 to $2614 \mathrm{keV}$ ). The attenuation properties of the $2614 \mathrm{keV}$ gamma line are of special importance in the reactor design circumstances.

The mass attenuation coefficients have been evaluated by the relation described by [6]-[10]

$$
\frac{\mu}{\rho}=\frac{\ln \left(\frac{I_{0}}{I}\right)}{\rho x}
$$

where $I_{0}$ is the initial photon density, $I$ is the photon density that penetrates the alloy distance $x$ and $\mu$ is the linear attenuation coefficient. Also tenth value layer can be calculated by:

$$
H V L=\frac{\operatorname{Ln}(2)}{\mu} .
$$

The effective atomic number $Z_{\text {eff }}$ of the steel alloys consisting of different elements is based on the determination of total attenuation cross section for $\gamma$ ray interactions and it can be obtained by the following formula [11] [12]:

$$
Z_{\text {eff }}=N_{A} \frac{\sum_{i} f_{i} A_{i}\left(\frac{\mu}{\rho}\right)_{i}}{\sum_{i} \frac{f_{i} A_{i}}{Z_{i}}\left(\frac{\mu}{\rho}\right)_{i}}
$$

where $N_{A}$ is the Avogadro's constant, $Z_{i}$ is the atomic number of the $i_{t h}$ element; $A_{i}$ and $f_{i}$ are atomic weights (in gram) and number of atoms of element $i$ relative to total number of atoms in the alloy respectively.

The chemical compositions of the cobalt-free alloy are presented in Table 1.

\section{Results and Discussions}

Total linear attenuation coefficient and half value layer for different energies have been measured at photon energies from 0.2 to $2.7 \mathrm{MeV}$.

The values of the linear attenuation coefficients $\mu$ for the investigated alloy at different energies as a function of thickness are shown in Figure 1.

It is shown that the linear attenuation coefficient is inversely proportional to the photon energy from 200 to $1100 \mathrm{keV}$, then it smoothly decreases with a less rate than in the low energy region.

The transmission rate is an important parameter for testing the shielding material. Figure 2 shows the transmission rate as a function of thickness at specified energies. Also the half value layers are shown in the graphs for each energy line. It is clear from that figure that the larger thickness of the material is needed for stopping the high energy.

The theoretical and experimental values of the total mass attenuation coefficient are presented in Figure 3. The correlation theory is used to confirm the linearity of theoretical and experimental values with a correlation coefficient $\left(R^{2}\right)$ about 0.97 . It can be noted that the calculated and measured values are in good agreement.

Table 1. Chemical composition of the investigated alloy.

\begin{tabular}{cccccccccc}
\hline Chemical composition & $\mathrm{Ni}$ & $\mathrm{Cr}$ & $\mathrm{Mo}$ & $\mathrm{Ti}$ & $\mathrm{V}$ & $\mathrm{C}$ \\
\hline wt\% & 12.73 & 6.53 & 3.2 & 0.02 & 0.01 & 0.045 & Balance \\
\hline
\end{tabular}




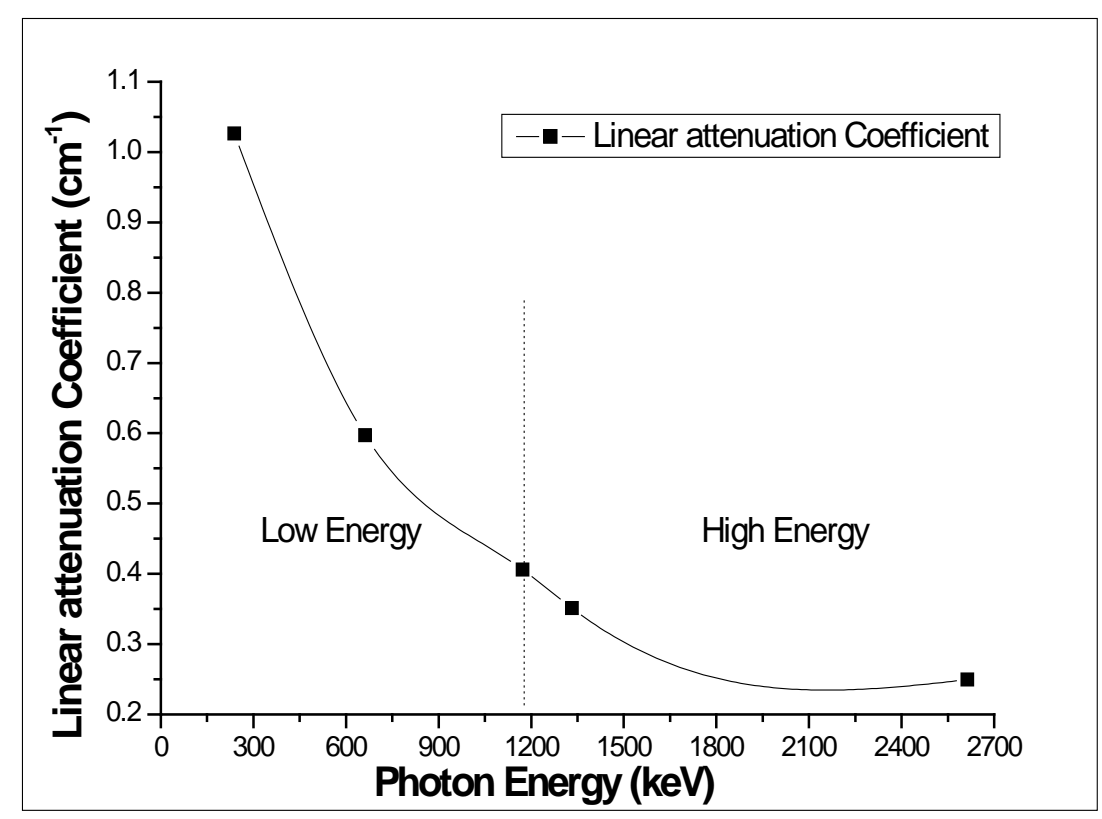

Figure 1. The linear attenuation coefficient versus the photon energy.

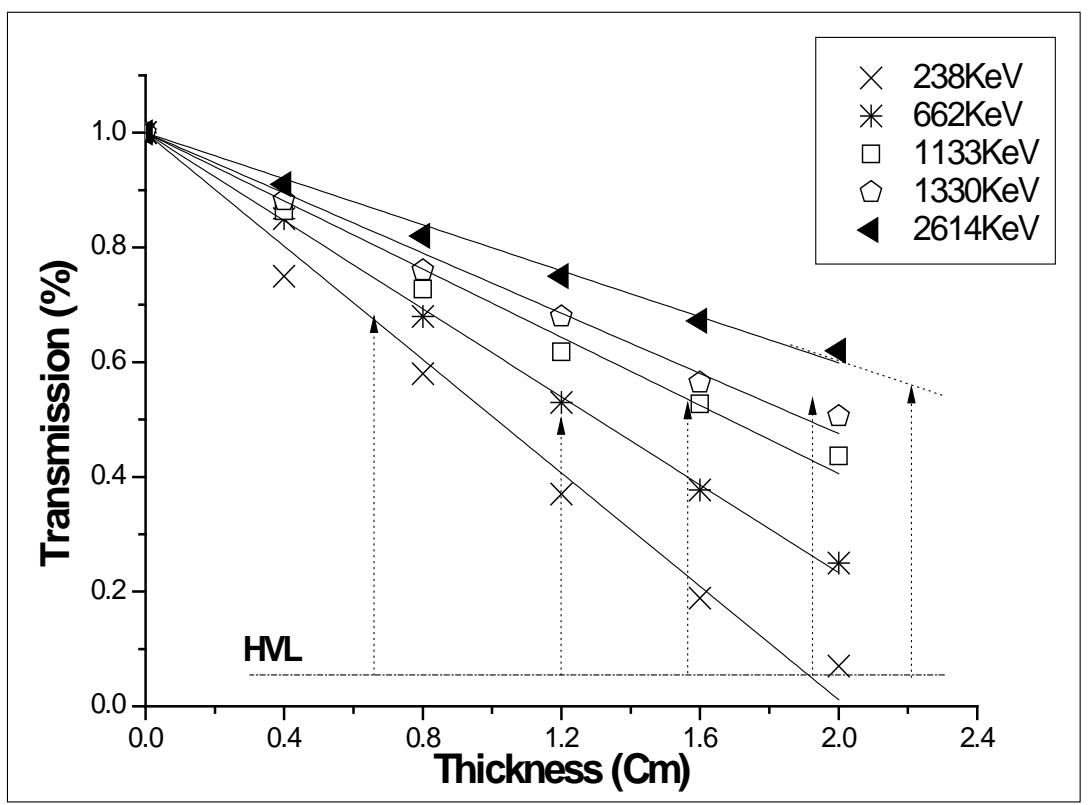

Figure 2. The percentage transmission for the new alloy as a function of thickness.

The effective atomic numbers $Z_{\text {eff }}$ at photon energies from 0.2 to $3.0 \mathrm{MeV}$ have been calculated for the steel alloy and the results have been displayed in Figure 4. It can be seen from this figure that the effective atomic number decreases with energy increase from $(0.2$ to $1.0 \mathrm{MeV})$, and then it slightly increases for higher energies.

\section{Conclusion}

New shielding cobalt-free steel "0.045\%C-12.73\%Ni-6.53\%Cr-3.2\%Mo-0.02\%Ti-0.01\%V", was developed by electro slag remelting technique. Mass attenuation coefficients, half value layers and effective atomic numbers of the new alloy have been evaluated. A comparison of the mass attenuation coefficient with the corresponding theoretical one (based on XCOM) has been done and a fair agreement is achieved. 


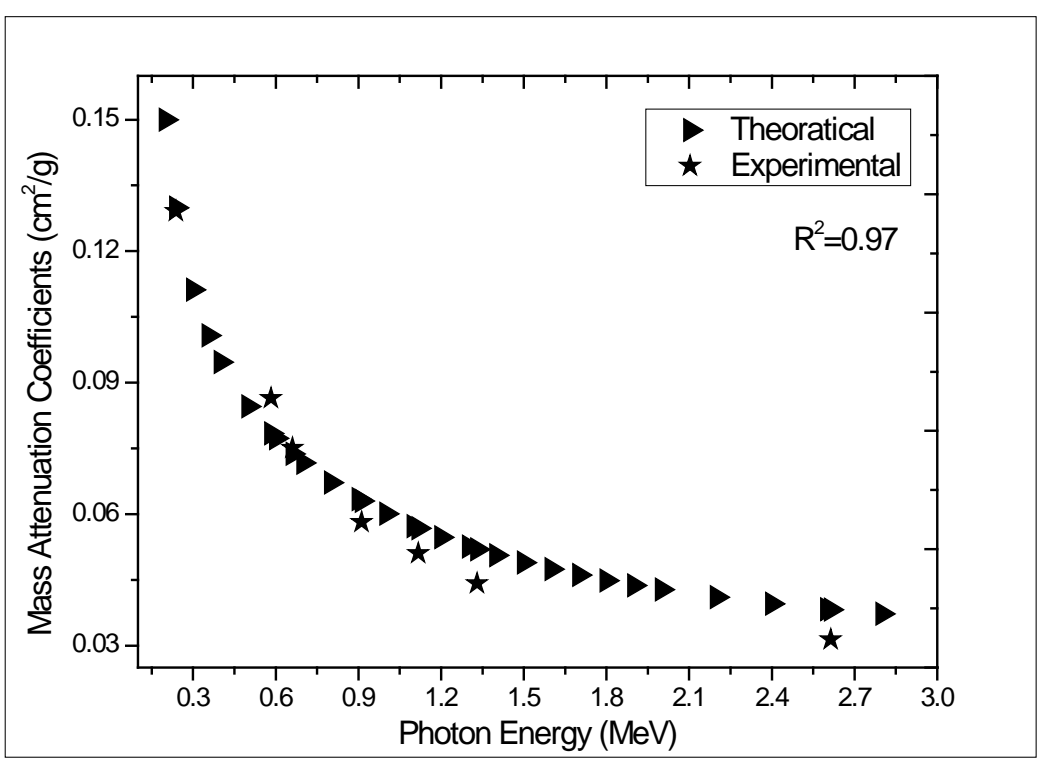

Figure 3. The total mass attenuation coefficients of the alloy as a function of the energy.

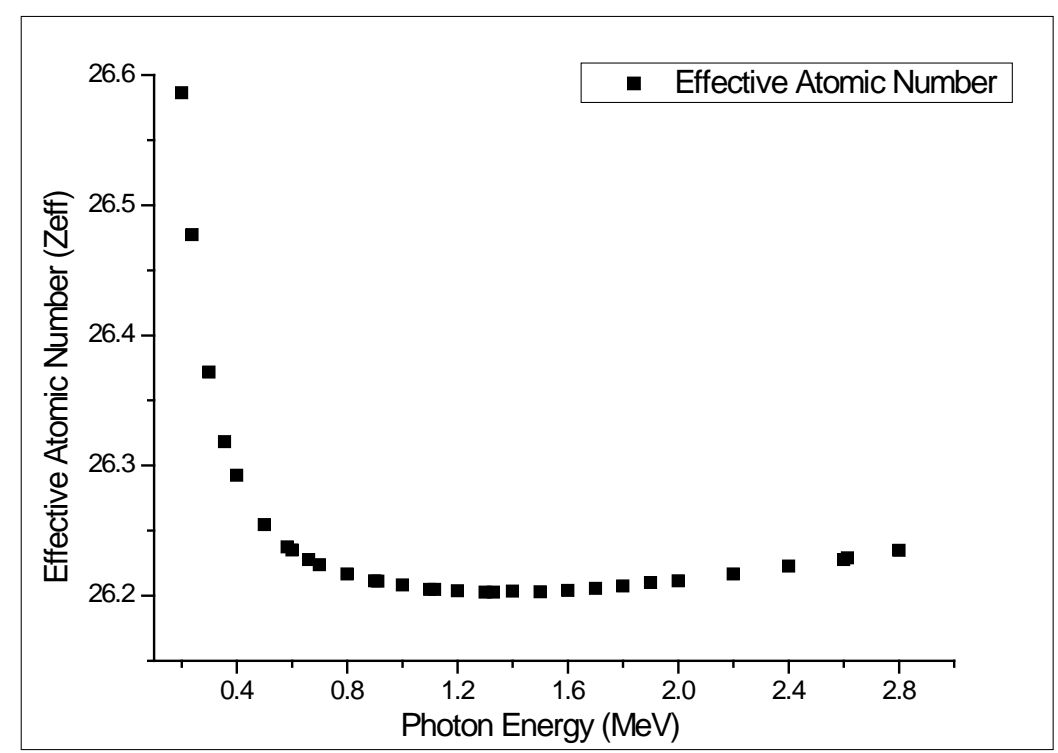

Figure 4. The effective atomic number as a function of the photon energy.

\section{Acknowledgements}

Special thanks to Prof S. El-kameesy and Prof M. Eissa lab groups, for their help.

\section{References}

[1] Kim, Y.G., et al. (1986) Microstructure and Mechanical Properties of a Cobalt-Free Tungsten-Bearing Maraging Steel. Materials Science and Engineering, 79, 133-140. http://dx.doi.org/10.1016/0025-5416(86)90396-4

[2] Leslie, W.C. and Hornbogen, E. (1996) Chapter 17-Physical Metallurgy of Steels. Physical Metallurgy. In: Cahn, R.W. and Haasen, P., Eds., 4th Edition, North-Holland, Oxford, 1555-1620. http://dx.doi.org/10.1016/B978-044489875-3/50022-3

[3] Prokoshkina, V.G. and Kaputkina, L.M. (2006) Structure Heredity, Aging and Stability of Strengthening of Cr-Ni Maraging Steels. Materials Science and Engineering: A, 438-440, 222-227. http://dx.doi.org/10.1016/j.msea.2006.02.075 
[4] He, Y., et al. (2006) Age Hardening and Mechanical Properties of a 2400 MPa Grade Cobalt-Free Maraging Steel. Metallurgical \& Materials Transactions, 37, 1107-1116. http://dx.doi.org/10.1007/s11661-006-1089-4

[5] Dautovich, D.P. (1976) 3.4-Corrosion Resistance of Maraging Steels. In: Shreir, L.L., Ed., Corrosion, Newnes, 3:64-3:76.

[6] Wood, J.I. (1982) Computational Methods in Reactor Shielding. Pergamon Press, New York.

[7] El-Khayatt, A.M. and Akkurt, İ. (2013) Photon Interaction, Energy Absorption and Neutron Removal Cross Section of Concrete including Marble. Annals of Nuclear Energy, 60, 8-14. http://dx.doi.org/10.1016/j.anucene.2013.04.021

[8] Kurudirek, M., et al. (2011) Analysis of Some Pb, Th and U Compounds in Terms of Photon Interaction, Photon Energy Absorption and Fast Neutron Attenuation. Radiation Physics and Chemistry, 80, 855-862. http://dx.doi.org/10.1016/j.radphyschem.2011.03.015

[9] Gong, J., et al. (2001) Effect of Load-Dependence of Hardness on Indentation Toughness Determination for SodaLime Glass. Journal of Non-Crystalline Solids, 282, 325-328. http://dx.doi.org/10.1016/S0022-3093(01)00341-6

[10] Akkurt, I. and El-Khayatt, A.M. (2013) Effective Atomic Number and Electron Density of Marble Concrete. Journal of Radioanalytical and Nuclear Chemistry, 295, 633-638. http://dx.doi.org/10.1007/s10967-012-2111-5

[11] Erdem, M., et al. (2010) A Novel Shielding Material Prepared from Solid Waste Containing Lead for Gamma Ray. Radiation Physics and Chemistry, 79, 917-922. http://dx.doi.org/10.1016/j.radphyschem.2010.04.009

[12] Y1lmaz, E., et al. (2011) Gamma Ray and Neutron Shielding Properties of Some Concrete Materials. Annals of Nuclear Energy, 38, 2204-2212. http://dx.doi.org/10.1016/j.anucene.2011.06.011 